\title{
Modulatory effects of cAMP and PKC activation on gap junctional intercellular communication among thymic epithelial cells
}

\author{
Oscar K Nihei ${ }^{1,2}$, Paula C Fonseca ${ }^{1}$, Nara M Rubim¹, Andre G Bonavita ${ }^{1}$, Jurandy SPO Lyra ${ }^{2,3}$, \\ Sandra Neves-dos-Santos ${ }^{2,4}$, Antonio C Campos de Carvalho ${ }^{5}$, David C Spray ${ }^{6}$, Wilson Savino ${ }^{2}$, Luiz A Alves ${ }^{1 *}$
}

\begin{abstract}
Background: We investigated the effects of the signaling molecules, cyclic AMP (CAMP) and protein-kinase C (PKC), on gap junctional intercellular communication (GJIC) between thymic epithelial cells (TEC).

Results: Treatment with 8-Br-CAMP, a CAMP analog; or forskolin, which stimulates CAMP production, resulted in an increase in dye transfer between adjacent TEC, inducing a three-fold enhancement in the mean fluorescence of coupled cells, ascertained by flow cytometry after calcein transfer. These treatments also increased Cx43 mRNA expression, and stimulated Cx43 protein accumulation in regions of intercellular contacts. VIP, adenosine, and epinephrine which may also signal through cyclic nucleotides were tested. The first two molecules did not mimic the effects of 8-Br-cAMP, however epinephrine was able to increase GJIC suggesting that this molecule functions as an endogenous inter-TEC GJIC modulators. Stimulation of PKC by phorbol-myristate-acetate inhibited inter-TEC GIC. Importantly, both the enhancing and the decreasing effects, respectively induced by CAMP and PKC, were observed in both mouse and human TEC preparations. Lastly, experiments using mouse thymocyte/TEC heterocellular co-cultures suggested that the presence of thymocytes does not affect the degree of inter-TEC GJIC.

Conclusions: Overall, our data indicate that CAMP and PKC intracellular pathways are involved in the homeostatic control of the gap junction-mediated communication in the thymic epithelium, exerting respectively a positive and negative role upon cell coupling. This control is phylogenetically conserved in the thymus, since it was seen in both mouse and human TEC preparations. Lastly, our work provides new clues for a better understanding of how the thymic epithelial network can work as a physiological syncytium.
\end{abstract}

\section{Background}

Intercellular communication mediated by gap junctions has been considered ubiquitous during the development, maturation, homeostasis and death of diverse cell types and tissues in metazoa [1-7]. These junctions are membrane specializations located in cell-cell contact regions, where intercellular hydrophilic conduits, assembled as dodecameric protein complexes, directly connect the cytosols of adjacent cells [8]. Each complex is composed by two hexameric hemichannels, the connexons, one in each cell $[9,10]$. In vertebrates, members of the connexin protein family form these channels, which in rodents

\footnotetext{
* Correspondence: alveslaa@ioc.fiocruz.br

'Laboratory of Cellular Communication, Oswaldo Cruz Institute, The Oswaldo
} Cruz Foundation, Rio de Janeiro, Brazil has at least 20 isoforms [11,12]. Topologically, the connexin protein contains four hydrophobic transmembrane domains (M1 to M4), two conserved extracellular loops (E1-E2), one intracellular loop and intracellular C- and $\mathrm{N}$-terminal domains [13]. With an estimated permeability limited to molecules below approximately $1 \mathrm{kDa}$, these intercellular channels allow cells to share metabolites such as glucose and nucleotides, buffer ions such as $\mathrm{K}^{+}$and $\mathrm{H}^{+}$, and convey important intracellular second messengers such as calcium, cyclic 5 '-adenosine monophosphate (cAMP) and 1,4,5-inositol-trisphosphate (IP3) [14-18]. Physiologically, gap junctions have been associated with diverse phenomena such as transmission of electrical signals (as electrotonic synapses) and intercellular calcium waves, metabolic and ionic coupling, and cellular synchronization [19-22]. In this respect, loss or 
dysfunction of gap junctions have been related to distinct diseases [23-28].

Gap junction channels may be modulated at different levels. Gap junction channel gating, i.e., shifting between open and closed states, is regulated by voltage, intracellular $\mathrm{pH}(\mathrm{pHi})$ and $\mathrm{Ca}^{2+}\left(\left[\mathrm{Ca}^{2+}\right] \mathrm{i}\right)$, and phosphorylation [29-31]. It has been suggested that the connexin Cterminal and the intracellular loop of the protein are associated with gap junction channel sensitivity to $\mathrm{pHi}$ and $\left[\mathrm{Ca}^{2+}\right] \mathrm{i}$, while the M1 domain, the $\mathrm{N}$-terminal and the E1 domain have been associated with the voltage sensor $[13,29]$. The $\mathrm{C}$-terminal domain exhibits diverse kinase recognition motifs, which allow channel regulation by threonine/serine and tyrosine kinases.

Functional GJIC has been shown in a variety of cell types of the immune system, such as $\mathrm{T}$ and $\mathrm{B}$ lymphocytes, dendritic cells, microglia, monocytes, macrophages, neutrophils and mast cells [32-38]. In vitro experiments have demonstrated $\mathrm{Cx} 43$ mediated functional GJIC between thymic epithelial cells $[39,40]$. In addition, data obtained from $\mathrm{Cx} 43^{-/-}$mice revealed that this protein is important to normal $\mathrm{T}$ cell lymphopoiesis [41].

Despite the multiple possibilities of regulation of thymic physiology by diverse neuroendocrine products [42], few previous studies have evaluated GJIC modulation in thymic epithelial cells. Head et al. [43,44] demonstrated, by dye injection, that treatment of thymic epithelial cells with soluble factors such as interleukin-1 (IL-1), growth hormone $(\mathrm{GH})$, adrenocorticotrophic hormone $(\mathrm{ACTH})$, steroid hormones and neuropeptides induced a partial inhibition of coupling and in some cases it diminished thymulin secretion.

The modulation of GJIC may also be evaluated through the activation of different intracellular signaling pathways by specific second messenger analogs, as well as agonists or antagonists of relevant signaling molecules. The importance of cAMP and PKC in mediating intracellular signaling of diverse extracellular messengers is widely recognized $[45,46]$. cAMP activates cAMPdependent protein kinase (PKA) [47]; and PKC is activated by diacylglycerol and/or calcium (or neither depending on its isoform), as a result of phospholipid signaling pathways [48]. The effects of cAMP on GJIC have been investigated in systems such as hepatocyte primary cultures, cardiac myocytes, ovarian follicles, myometrium, carotid body and retina [15,49-53]; and in cell lines derived from ovarian granulosa cells, endometrial and colonic epithelium, endothelium, osteoblasts, and mammary tumor cells [54-57].

The effects of PKC activation on GJIC have also been investigated [31]. In general, cAMP acts by enhancing GIC while PKC inhibits it [49,51,57-59]. However, contrasting results have been reported for both signaling pathways $[15,50,53,56,60]$. Nevertheless, to our knowledge the effects of cAMP elevation or PKC activation on GJIC have not been studied in the immune system. Herein we investigated the putative modulatory effects of cAMP and PKC on GJIC between thymic epithelial cells (TEC). Our results demonstrate that inter-TEC GJIC is upregulated by cAMP and downregulated by PKC.

\section{Results}

\section{Evaluation of functional GJIC-mediated dye transfer by flow cytometry}

Confirming previous results from our Laboratory $[39,61,62]$ flow cytometry experiments revealed that after 6 hours of co-culture more than $65 \%$ of the initial single positive DiIc $_{18}(3)^{+}$TEC acquired calcein (Figure 1B). To ascertain that gap junctions mediated this dye transfer we treated the cells for $6 \mathrm{hrs}$ with $100 \mu \mathrm{M}$ of $18-\beta$-glycyrrhetinic acid (GRA), a gap junction inhibitor. Such procedure inhibited inter-TEC GJIC by $>85 \%$ (Figure $1 C$ ). Similar results were also obtained when the epithelial were treated with carbenoxolone, another gap junction inhibitor (data not shown).

\section{CAMP elevation enhances inter-TEC GJC}

To analyze the putative modulatory effects of cAMP on GJIC in TEC cultures, we stimulated the mouse TEC line with 8-Br-cAMP, a membrane permeable cAMP analog; or forskolin, which stimulates cAMP production through activation of adenylate cyclase isoforms [63]. For that, TEC co-cultures were either treated or not with 8 -Br-cAMP $(1 \mathrm{mM})$ or forskolin $(10 \mu \mathrm{M})$ for $6 \mathrm{hrs}$ and subsequently analyzed by flow cytometry. Two distinct quantitative parameters were calculated comparing the treated versus control double positive TEC: the extent of cell coupling (\% double positive cells) and the cell coupling efficiency (based on calcein geometric mean fluorescence). Under these conditions, the extent of coupling was not significantly modified, ranging from $85.0 \pm 8.2 \%$ (Mean \pm SD) at control level to up to 96.7 $\pm 1.9 \%$ and $95.5 \pm 2.2 \%$ with 8 -Br-cAMP and forskolin, respectively, indicating that the TEC monolayer was functionally well coupled under control confluent culture conditions (Figure 2A-D). Nevertheless, treatment with 8-Br-cAMP or forskolin increased transfer efficiency, inducing respectively, $3.21 \pm 0.58$ and $3.18 \pm$ 0.29 fold increase in geometric mean fluorescence of calcein labeling in double positive cells (Figure 2A-D). The half maximal effective concentration $\left(\mathrm{EC}_{50}\right)$ for 8Br-cAMP and forskolin was $98 \mu \mathrm{M}$ and $0.470 \mu \mathrm{M}$, respectively (Figure 2E-H). Importantly, upregulation of inter-TEC GJIC triggered by 8-Br-cAMP was not restricted to the mouse TEC line, since similar results were seen when TNC-derived primary cultures of human TEC (Figure 2I) and IT76 M1 cells (data not 


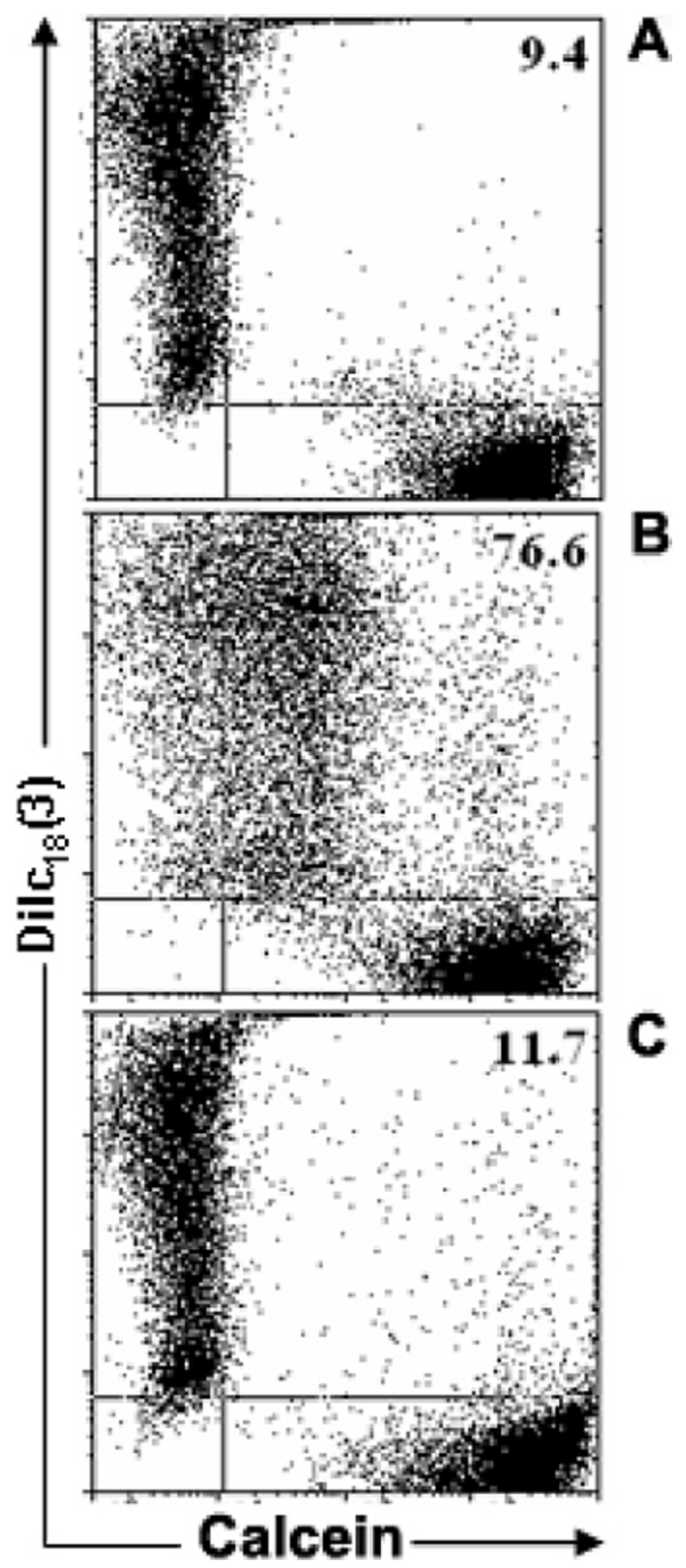

Figure 1 Flow cytometric analysis of the mouse thymic epithelial cell line, showing inter-TEC gap junction intercellular communication. Calcein ${ }^{+}$Dil $_{18}(3)^{-}$and calcein ${ }^{-}$Dilc $_{18}(3)^{+}$IT-76M1 cells were co-cultured for $6 \mathrm{hr}$ at $37^{\circ} \mathrm{C}$. These cells were then dissociated and analyzed by flow cytometry to quantify the double positive $\left[\right.$ calcein $^{+}$Dilc $_{18}(3)^{+}$] cells. Some calcein ${ }^{+} \operatorname{Dilc}_{18}(3)^{-}$and calcein Dilc $_{18}(3)^{+}$cells were separately cultured and used to adjust the cytometry settings. These cells also were used to establish the control population (A). Data are presented in the form of dot plots (A, B, C), which depict two-dimensionally the labeling pattern of each cell population considering the fluorescence intensity (log scale) of calcein and Dilc ${ }_{18}(3)$. In $\mathbf{B}$, the $6 \mathrm{hr}$ co-cultured cells are shown, where the presence of double positive cells is apparent, indicating the dye coupling. In C, cells co-cultured for 6 hours in the presence of 18- $\beta$-glycyrrhetinic acid (GRA; $100 \mu \mathrm{M}$ ) exhibited a complete inhibition of inter-TEC GJIC. These data are representative of at least 4 experiments. shown) were treated with 8-Br-cAMP, as ascertained after lucifer yellow microinjection and blind evaluation of the numbers of coupled cells.

We observed the same effect when the intracellular dye microinjection assay was performed on IT76M1 cells.

We also tested if inter-TEC GJIC could be modulated by distinct extracellular messenger molecules, which also signal through cyclic nucleotides. For that we applied the vasoactive intestinal peptide (VIP), adenosine and epinephrine. $\mathrm{VIP}^{+}$nerve terminals and VIP receptors have been characterized in thymic parenchyma $[64,65]$, whereas adenosine, which activates P1 receptors, has been implicated in thymocyte death $[66,67]$ and epinephrine, a systemic catecholamine, whose actions include control of TEC cytokine secretion [68]. We treated mouse TEC line cultures with increasing concentrations of VIP ( $1 \mathrm{nM}$ to $1 \mu \mathrm{M})$, adenosine ( $1 \mathrm{nM}$ to 100 $\mu \mathrm{M})$ and epinephrine $(100 \mathrm{nM}$ to $1 \mu \mathrm{M})$. Neither VIP (Figure 3A-F) nor adenosine (Figure 3G) changed in the extent of inter-TEC GJIC. However, treatment with the adrenoreceptor agonist epinephrine induced an increase on dye coupling in a dose-dependent manner (Figure $3 \mathrm{H})$.

\section{cAMP elevation upregulates $\mathrm{Cx} 43$ at different levels}

We also investigated the possible mechanisms underlying the GJIC stimulatory effects of cAMP elevation. When mouse TECs were evaluated by immunofluorescence, the labeling pattern generated with the anti-Cx43 antibody revealed that both $8-\mathrm{Br}$-cAMP and forskolin induced an accumulation of $\mathrm{Cx} 43$ protein at regions of intercellular contacts, presenting a punctate pattern of distribution (Figure 4A-F). The northern blot analysis revealed an increase in Cx43 mRNA as early as $1 \mathrm{hr}$ after the treatment with 8-Br-cAMP, which continued to be observed after 6 and 24 hours of treatment (Figure $4 G)$.

Phorbol ester induced PKC activation and down-regulates inter-TEC GJIC

PKC is a serine/threonine protein kinase that phosphorylates gap junctions and these events have been correlated with the reduction of gap junction communication [69]. Consistent with this finding, and in contrast to cAMP, when mouse TECs were treated with PMA (which activates PKC), a decrease of dye coupling was observed, reducing from $69.26 \pm 12.29 \%$ at control conditions to $37.74 \pm 12.42 \%$ and $25.77 \pm 0.014 \%$ with PMA at 10 and $100 \mathrm{ng} / \mathrm{ml}$, respectively (Figure 5A-F), which represents a dye coupling inhibition of up to $60 \%$. The remaining coupled TEC was not significantly affected after PMA treatment (data not show). A similar down regulation of inter-TEC GJIC was seen in TNCderived human TEC primary cultures (Figure 5F). Herein we applied microinjection of Lucifer yellow, 


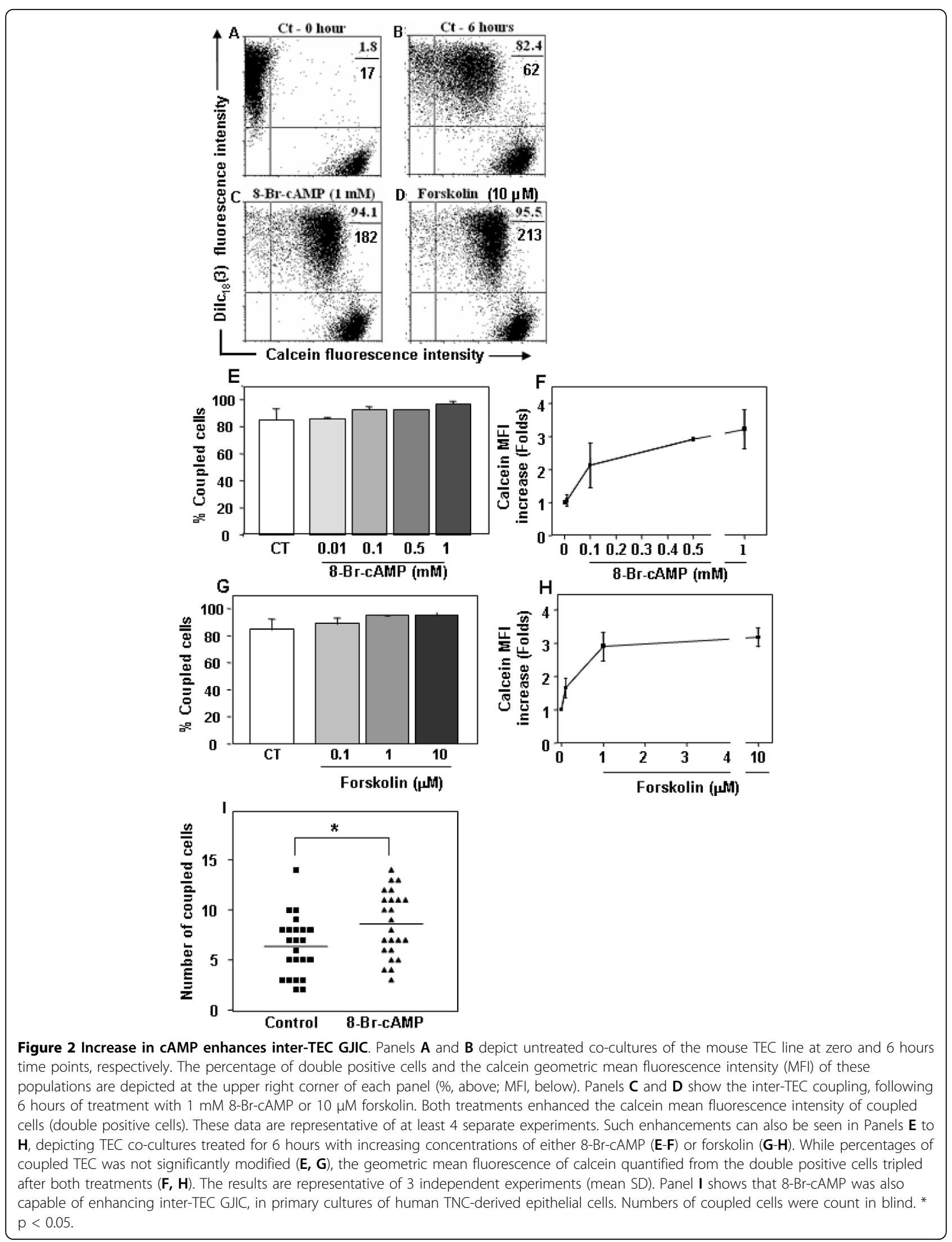



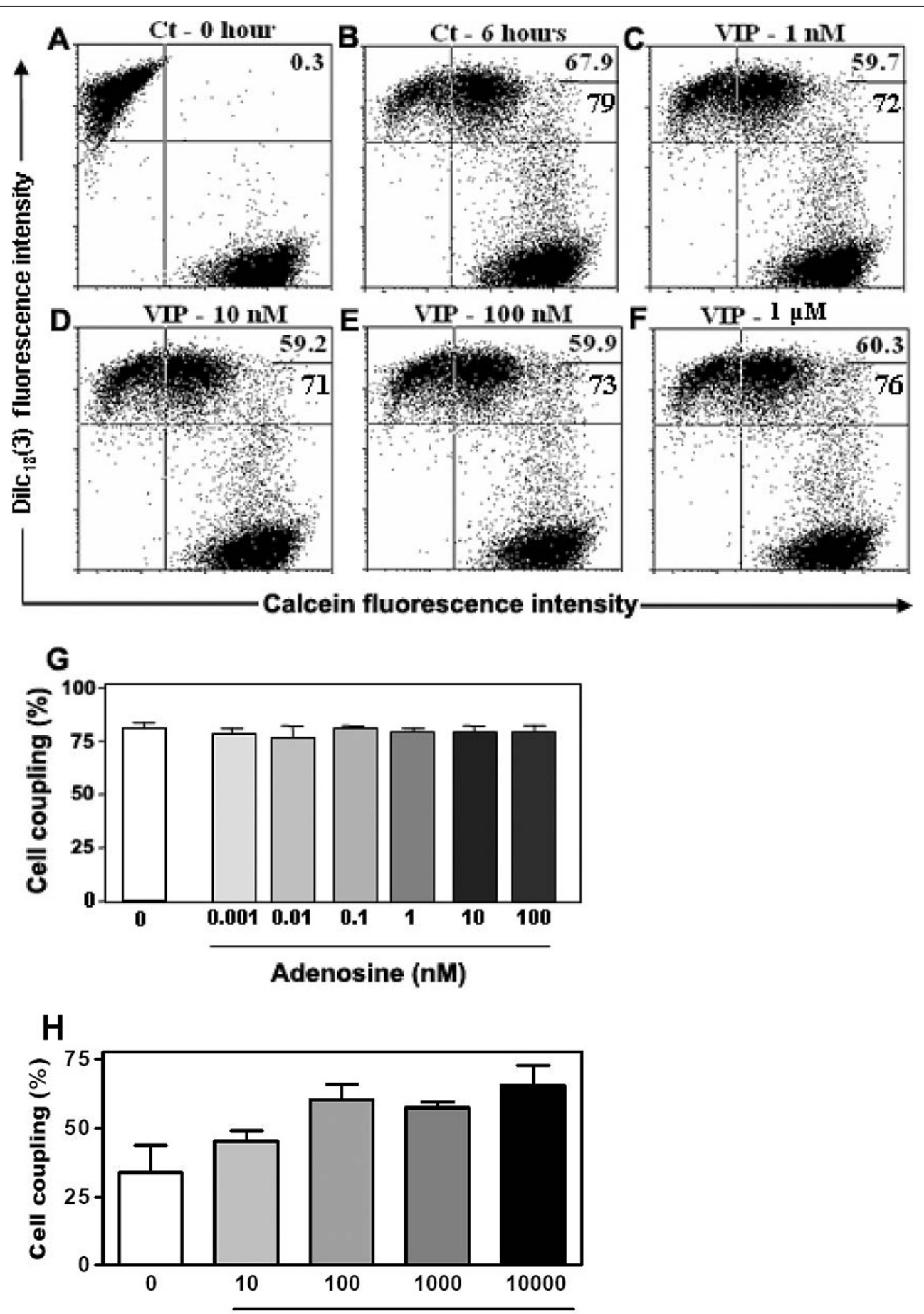

Epinephrine (nM)

Figure 3 Vasoactive intestinal peptide (VIP), adenosine and epinephrine effects on basal levels of inter-TEC GJIC. Co-cultures of the mouse TEC line were either treated or not (Ct- 6 hrs) with increasing concentrations of VIP (1-1000 nM, panels $\mathbf{C}$ to $\mathbf{F})$, and the degree of cell coupling, ascertained by cytofluorometry, did not change as compared to the 6 hours untreated control (B), in relation to both percentages of coupled cells and calcein mean fluorescence. Values are shown at the upper right corner of each panel, representing the percentage of double positive cells (above) and the calcein geometric mean fluorescence intensity (below) of these populations. Panel $\mathbf{A}$ depicts the flow cytometry profiles of TEC that were not co-cultured. Panel G shows that adenosine does not alter inter-TEC GJIC as well, as revealed by the percentages of coupled cells seen after treatment of various doses of the nucleotide. Panel $\mathbf{H}$ shows that epinephrine ( $1 \mathrm{nM}$ to $10 \mu \mathrm{M})$ increased the percentage of dye coupling between TEC in a dose-dependent fashion. Data are shown as mean \pm standard deviation, being representative of 2 independent experiments performed in triplicate. 


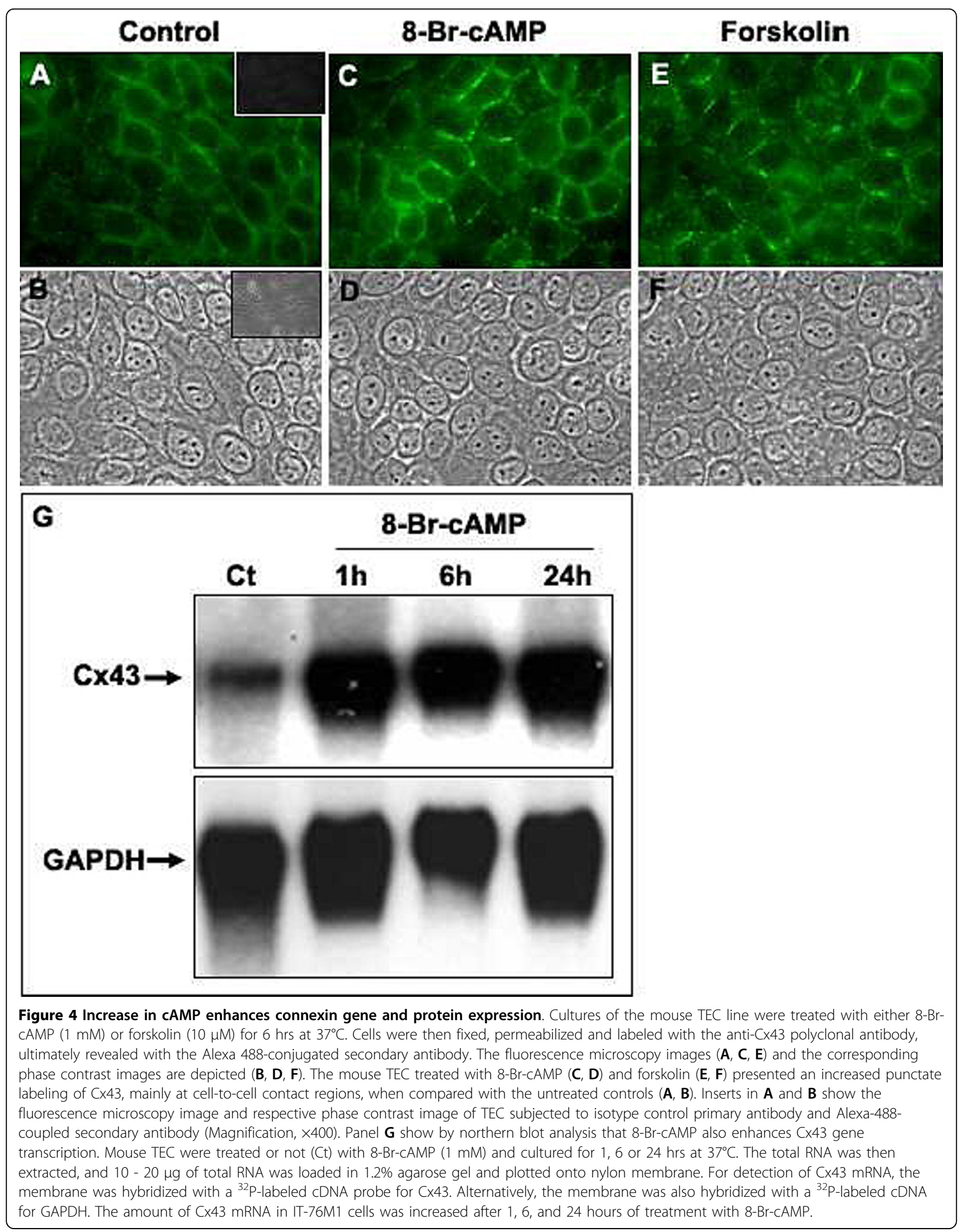


followed by blind counting of coupled cells. Confirming the participation of gap junctions in this process, $5 \mathrm{mM}$ heptanol completely inhibited dye coupling among human TEC (Figure 5F).

Since the phospholipid signaling frequently induces both PKC activation and $\left[\mathrm{Ca}^{2+}\right]$ i elevation, we also treated the mouse TEC line with both PMA and the calcium ionophore ionomycin $(1 \mu \mathrm{g} / \mathrm{ml})$. In these conditions, a partial but statistically significant inhibition of dye coupling was still seen (Figure 5G).

\section{Inter-TEC GJIC is not modulated by the presence of thymocytes}

Since thymocytes play an important role in TEC differentiation and organization during ontogeny of the thymus [70,71], we investigated if the contact with thymocytes could modulate GJIC in the thymic epithelium.

After the adhesion and establishment of mouse TEC co-cultures [containing calcein ${ }^{+} \operatorname{DiIc}_{18}(3)^{-}$and calcein $^{-}$ $\operatorname{DiIc}_{18}(3)^{+}$cells], the thymocytes were added at 5 fold or 10 fold excess over TECs. After an additional 5 hours, the thymocytes were discarded and the TEC co-cultures were dissociated and analyzed by flow cytometry. In these conditions, the dye coupling between adjacent TEC was not significantly modulated by thymocytes, neither at 1:5 nor at 1:10 TEC:thymocytes proportions (Figure 6). The calcein fluorescence intensity of calcein ${ }^{+} \operatorname{DiIc}_{18}(3)^{+}$ was not significantly modified as well (Figure 6).

\section{Discussion}

In the present study we demonstrated, by various experimental approaches, that cAMP and PKC are involved in the modulation of inter-TEC GJIC: the cAMP agonist 8-Br-cAMP enhanced inter-TEC coupling whereas PMA-induced PKC activation triggered an opposite effect.

Using flow cytometry we first detected in a mouse TEC line, that up to $90 \%$ of $\operatorname{DiIc}_{18}(3)^{+}$cells co-cultured in $1: 1$ ratio with calcein + cells became double positive, a phenomenon which was readily inhibited by the gap junction inhibitors $18-\beta$-glycyrrhetinic acid and carbenoxolone. This result clearly demonstrates that the thymic epithelium spontaneously forms a GJIC-dependent functional syncytium in vitro. Under these conditions, 8Br-cAMP and forskolin did not significantly modify this spontaneous percentage of coupled cells. However, both compounds enhanced up to 3 fold the calcein fluorescence intensity of the double positive cells, indicating an increase in the rate of dye transfer among coupled cells. Importantly, 8-Br-cAMP also induced an increment in GJIC in TNC-derived primary cultures of human TEC. These data clearly show that elevation of cAMP upregulates inter-TEC GJIC, similar to what has been reported for effects on cell types in other systems $[51,55]$.
Experiments performed with the mouse TEC line revealed that 8 -Br-cAMP and forskolin treatments induced an accumulation of $\mathrm{Cx} 43$ protein at cell-to-cell contact regions, seen as punctate clusters. Furthermore, 8-Br-cAMP induced an increase in Cx43 gene transcription, suggesting that the protein accumulation may be a consequence of altered Cx43 protein translation. Such an alteration in connexin synthesis and accumulation in the cell membrane is in accordance with previous description of modulation of gap junctions by cAMP elevating agonists after long-term evaluations (2-24 hrs, and 7 days) $[51,52,54,57,72-74]$. However, short-term modulation also has been demonstrated, with description of changes in gap junctional conductance within minutes of treatment with 8-Br-cAMP [75-77]; in some cell types, changes in dye coupling were also detected within 2-10 minutes after this treatment [55,56,77]. In cases of both short- and long-term evaluations alteration in the degree of connexin phosphorylation has also been demonstrated [73,76]. Interestingly, some of these reports have demonstrated that connexin isoforms other than $\mathrm{Cx} 43$ also may be regulated by cAMP analogs, such as Cx26, Cx40 and possibly Cx32 [49,56,76,77]. Thus, we cannot exclude the possibility that other connexin isoforms, not yet characterized in TEC, might also be regulated by $8-\mathrm{Br}-\mathrm{cAMP}$ and forskolin in IT-76M1 cells.

We also investigated whether physiological stimuli, could signal through cyclic nucleotides, might be involved in modulation of inter-TEC GJIC. When we evaluated VIP and adenosine, we did not observe any change in the degree of cell coupling in the mouse TEC preparation in any concentration of each molecule used. Similar results were seen despite the various concentrations applied for each molecule.

We should mention however, that our finding on VIP is at variance with the data reported by Head and coworkers [44]. These authors reported an inhibition of GJIC in a rat TEC. Although by now we cannot explain such a difference, it may be related to cell line variations or presumably due to receptor signaling dynamics that cannot be merely mimicked by a single agonist [78], or may be related to differences in methodological approaches given that the authors treated the cells before GJIC formation.

In any case, adenosine, which may also signal through cyclic nucleotides depending on its concentration and the activated P1 receptor [67], did not modify the basal level of inter-TEC GJIC as well. These results demonstrate that VIP and adenosine possibly are not physiological modulators of GJIC among TECs. A recent review indicates that adrenoreceptor agonists mediate thymus homeostasis and local $\mathrm{T}$ cell development [79]. In addition, reports have suggested a role for catecholamines 

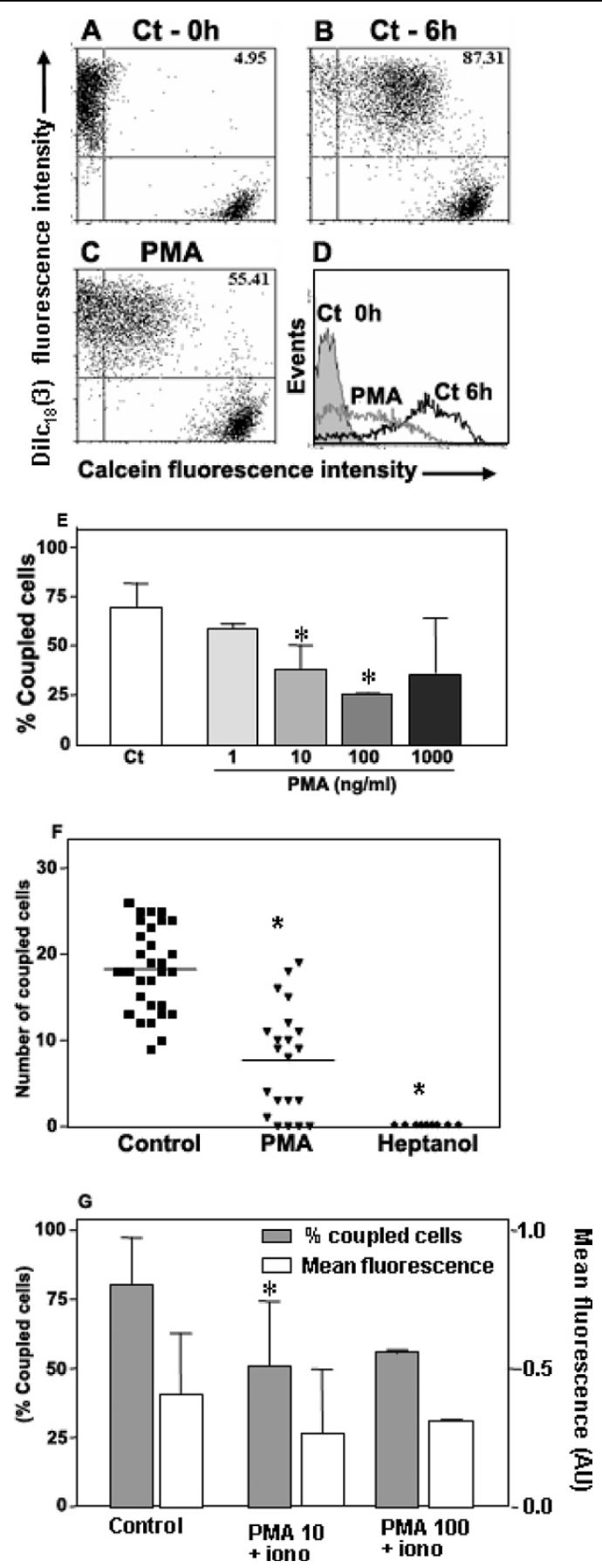

Figure 5 Phorbol myristate acetate inhibits GJIC in mouse and human TEC. Panels $\mathbf{A}$ to $\mathbf{D}$ are flow cytometry profiles showing mouse TEC co-cultures that were either treated $(\mathbf{C})$ or not $(\mathbf{B})$ with PMA $(10 \mathrm{ng} / \mathrm{ml})$ and maintained for $6 \mathrm{hrs}$ at $37^{\circ} \mathrm{C}$. Panel $\mathbf{A}$ represents the TEC population, which was separately cultured (Ct - 0 hours). The percentage of double positive cells is depicted at the upper right corner of each panel. The histograms with the calcein fluorescence profile of each population are depicted in panel $\mathbf{D}$ : calcein ${ }^{-} D_{i l} c_{18}(3)^{+}$cells, not submitted to co-culture (gray filled profile); control co-cultured TEC (black line); co-cultured TEC treated with PMA (gray line). Data are representative of at least 4 experiments. Panel $\mathbf{E}$ shows a dose-response curve of the effect of PMA treatment upon inter-TEC GJIC. A significant dose-dependent inhibition of cell coupling is seen, with a plateau being reached in $100 \mathrm{ng} / \mathrm{ml}$. ( $\left.{ }^{*} p<0.05\right)$. Panel $\mathbf{F}$ shows that PMA also down-regulates $\mathrm{GJIC}$ in primary cultures of TNC-derived human TEC. Panel $\mathbf{G}$ shows that simultaneous treatment with PMA and ionomycin also significantly inhibited dye coupling among TEC (* $p<0.05)$. Co-cultures of the mouse TEC line were treated simultaneously with PMA (10 or $100 \mathrm{ng} / \mathrm{ml})$ and ionomycin $(1 \mathrm{\mu g} / \mathrm{ml})$ for $6 \mathrm{hrs}$ at $37^{\circ} \mathrm{C}$, analyzed by flow cytometry. The percentage of coupled cells and the calcein geometric mean fluorescence obtained from double positive cells (Mean \pm SD) are shown. The data are representative of two independent experiments performed in triplicate. 


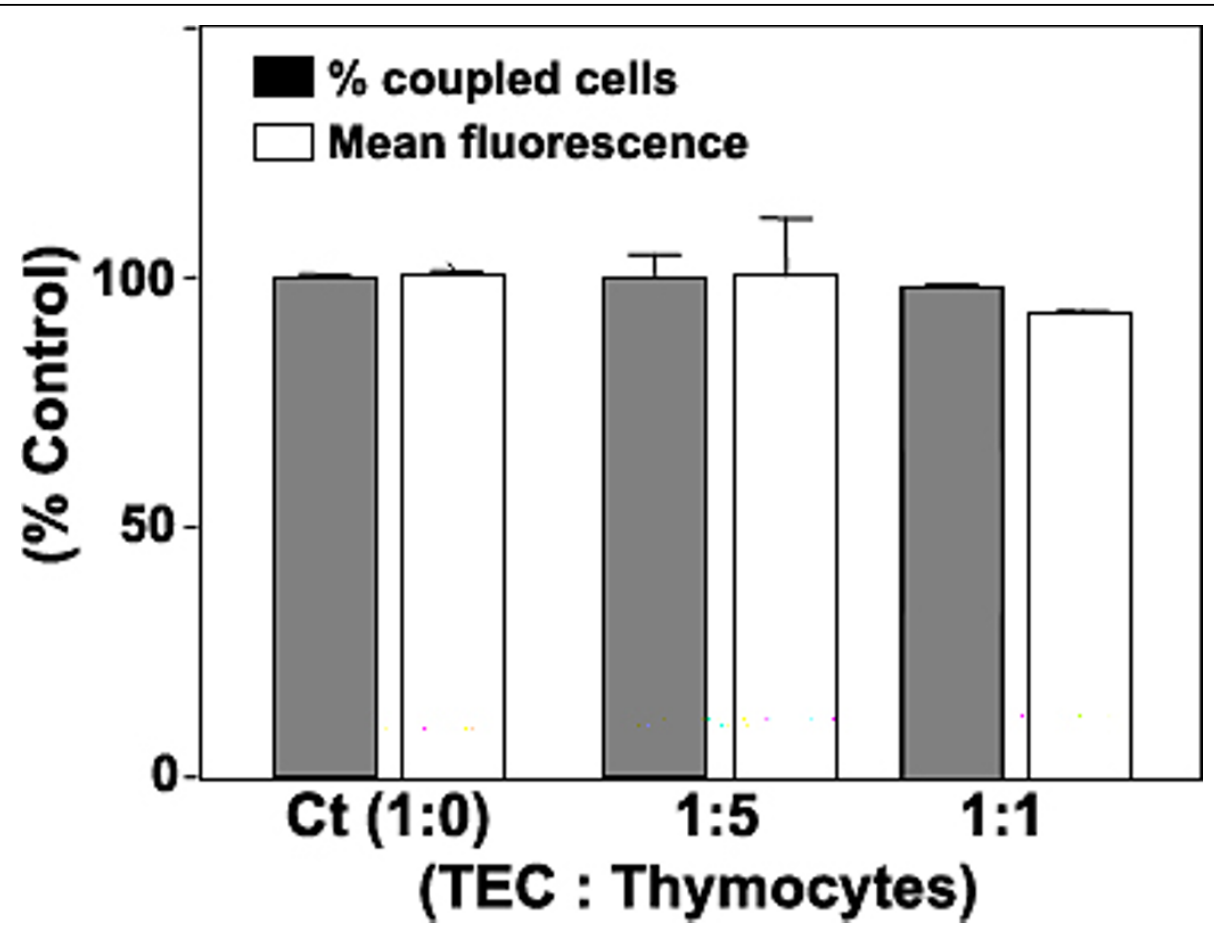

Figure 6 The presence of thymocytes do not change inter-TEC GJIC. Mouse TEC co-cultures (IT-76M1 cells) were maintained at $37^{\circ} \mathrm{C}$ for 2 hrs to establish an adherent confluent monolayer, and then simultaneously cultured with murine thymocytes at 1:5 or 1:10 (TEC:thymocytes) proportion for additional 5 hrs. After this incubation the thymocytes were discarded and epithelial cells were dissociated and analyzed by flow cytometry. The normalized dye coupling degree (gray columns) and the calcein mean fluorescence (white columns) of the double positive cells, clearly show the presence of thymocytes did not significantly modify the levels of dye coupling and dye transfer efficiency among mouse TEC. Data are expressed as mean SD, being derived from obtained from three independent experiments.

on thymic epithelial cells controlling proliferation and cytokine secretion $[68,80]$. Our data demonstrate that epinephrine, and activation of cAMP, lead to an increasing dye coupling in TEC cells suggesting that this mediator could endogenously control communication between thymic epithelial cells and contribute to thymus physiology. We are currently investigating other endogenous molecules which also signal through cAMP, in order to evaluate its potential to modulate inter-TEC GIIC.

In a second set of experiments, we demonstrated that PKC activation (induced herein by the phorbol ester, PMA) significantly inhibits the dye coupling in both mouse and human TEC in vitro models.

The fact that the same inhibitory effect was seen in a mouse TEC line as well as in primary cultures of human TEC deserve further discussion. The study by Chanson et al. [56] demonstrated that GJIC inhibition was induced by phorbol esters in a liver-derived cell line but not in differentiated primarily cultures of pancreatic exocrine cells. Similarly, the inhibitory effect of phorbol esters on GJIC was observed in primary cultured developing lens cells, which express Cx43 and Cx49, but not in lentoid cells (differentiated lens cells), which express
Cx46 and Cx49, demonstrating that the effects of these compounds might be dependent on the cellular differentiation stage and its pattern of Cx expression [81].

By contrast, the presence of thymocytes apparently is not involved in the control of inter-TEC GJIC, at least in the co-culture experimental conditions that we used. Nevertheless, further studies are still necessary in order to completely discard a role for thymocytes in the control of inter-TEC communication mediated by gap junctions.

\section{Conclusions}

In summary, our data strongly indicate that cAMP and PKC intracellular pathways are involved in the homeostatic control of the gap junction-mediated communication in the thymic epithelium, exerting respectively a positive and negative role upon cell coupling. Importantly, this control is phylogenetically conserved in the thymus, since it was seen in both mouse and human TEC preparations.

In a second vein, we showed that two other extracellular messenger molecules, which also signal through cyclic nucleotides, VIP and adenosine, did not mimic the positive action of 8 -Br-cAMP, but epinephrine was able 
to reproduce this effect, suggesting a specificity control of cAMP in the mechanism of inter-TEC GJIC.

Overall, our work provides new clues for a better understanding of how the thymic epithelial network can work as a physiological syncytium.

\section{Methods}

\section{Chemicals}

Lucifer yellow, triton X-100, 18- $\beta$-glycyrrhetinic acid (GRA), forskolin, 8-bromoadenosine 3',5'-cyclic monophosphate (8-Br-cAMP), phorbol 12- myristate 13-acetate (PMA) and ionomycin were purchased from Sigma Chemical Co. (St. Louis, MO, USA). Calcein-AM and $\operatorname{DiIc}_{18}(3)$ dyes were obtained from Molecular Probes (Eugene, OR, USA), and heptanol was from Merk (Darmstadt, Germany). Collagenase A, dispase II and DNAse grade II were purchased from Boehringer Mannheim Biochemicals (Indianapolis, IN, USA), whereas fetal calf serum was from Hyclone Laboratories (South Logan, UT, USA).

\section{Thymic epithelial cultures}

The mouse TEC line, IT-76M1, was obtained from $\mathrm{BALB} / \mathrm{c}$-derived thymic stromal cells after continuous culture. The epithelial nature of this line was ascertained by the presence of desmosomes and cytokeratin filaments [82-84]. These cells were routinely maintained in culture with RPMI 1640 medium supplemented with $10 \%$ fetal bovine serum, at $37^{\circ} \mathrm{C}$ in a $5 \% \mathrm{CO} 2$ atmosphere.

In addition to the mouse TEC line, we used in some experiments, primary cultures of human TEC, obtained after isolation of thymic nurse cells complexes. For that, fragments of human thymus were obtained from children subjected to cardiac surgery, following the guidelines of the Oswaldo Cruz Foundation's ethics committee. Thymic nurse cells (TNC) are thymic lymphoepithelial complexes that harbor a variable number of thymocytes [85]. When settled in culture, TNCs gradually release thymocytes, and after 3-5 days, a thymocyte-free primary culture of epithelial cells is established. The TNC isolation was performed according to the procedures currently done in our laboratory [86]. In brief, human thymic fragments were minced $\left(\sim 1 \mathrm{~mm}^{3}\right)$ and gently agitated for $20 \mathrm{~min}$ in RPMI 1640 medium. Released thymocytes were discarded and the thymic fragments were suspended in collagenase A solution $(0.2$ $\mathrm{mg} / \mathrm{mL}$ ) and further agitated at room temperature (RT) for $20 \mathrm{~min}$. The supernatant was again discarded and the remaining fragments were dissociated enzymatically with a CDD solution (collagenase A $-0.2 \mathrm{mg} / \mathrm{mL}$; dispase II $-0.2 \mathrm{mg} / \mathrm{mL}$; DNAse grade II $-5 \mu \mathrm{g} / \mathrm{ml}$ ) for 20 min at $37^{\circ} \mathrm{C}$. The digestion product was centrifuged and the pellet suspended in PBS. These cell suspensions were carefully layered above $10 \mathrm{~mL}$ of fetal calf serum
(Cultilab, Campinas, Brazil) placed in $15 \mathrm{~mL}$ tubes. The typically heavier TNCs were allowed to sediment. The TNCs obtained by this process were cultured, and after complete thymocyte release, resulting epithelial cultures were used in all experiments.

\section{Immunofluorescence}

To evaluate connexin expression, TEC were cultured on glass coverslips until confluence. The cells were fixed in cold $\left(-20^{\circ} \mathrm{C}\right)$ methanol and further permeabilized by a solution containing $0.2 \%$ Triton $\mathrm{X}-100$. The cells were then incubated overnight at $4^{\circ} \mathrm{C}$ with anti-connexin 43 rabbit polyclonal antibody (Zymed Laboratories, South San Francisco, CA, USA). After washing, the cells were incubated for 1 hour at room temperature with appropriate alexa 488-conjugated secondary antibody (Molecular Probes, Eugene, OR, USA) to reveal the specific labeling. The cells were washed twice, and the coverslips were mounted in PBS-glycerol (3:1) containing 0.1\% para-phenylene diamine, an anti-oxidation agent. Cells were analyzed in a Nikon Eclipse TE-300 microscope with phase-contrast and epifluorescence optics, and photographed using a SPOT-RT digital camera (Diagnostic Instruments, Sterling Heights, Michigan, USA).

\section{Dye microinjection assay}

The evaluation of GIIC by intracellular dye microinjection assay was performed as previously described [39]. Human TNC-derived epithelial cells and IT76 M1 cells were cultured in small Petri dishes until confluence. Visualization of cells was performed with an inverted microscope equipped with epifluorescence optics (Axiovert 100, Carl Zeiss, Oberkochen, Germain). The glass microelectrodes were pulled from borosilicate glass (World Precision Instruments, New Haven, CT, USA) using a pipette puller (model PC-10, Narishige, Tokyo, Japan), filled with lucifer yellow $(50 \mathrm{mg} / \mathrm{ml}$ in $150 \mathrm{mM}$ $\mathrm{LiCl})$ and positioned using a three-dimensional micromanipulator model (MMO-203, Narishige, Tokyo, Japan). Cells were then iontophoretically microinjected with lucifer yellow through brief current pulses. After 1 minute, the number of adjacent cells that acquired the lucifer yellow was quantified. To ascertain that the dye coupling was mediated by GJIC, in some experiments human TEC were also treated with heptanol $(5 \mathrm{mM})$, a gap junction inhibitor.

\section{Cytofluorometry}

GJIC was evaluated using flow cytometry as previously described $[61,87]$. After confluence, one sample of the mouse TEC line was loaded with calcein-AM $(0.5 \mathrm{M})$ for 30 minutes, while the other was labeled with the lipophilic molecule $\operatorname{Dilc}_{18}(3)(10 \mu \mathrm{M})$ for 1 hour. Cells were then washed 5 times with PBS and enzymatically dissociated. Calcein ${ }^{+} \operatorname{DiIc}_{18}(3)^{-}$cells and calcein ${ }^{-} \operatorname{DiIc}_{18}(3)$ ${ }^{+}$cells were co-cultured at 1:1 ratio, being treated (during the co-culture period of 6 hours) or not with drugs 
of interest. Thereafter, cells were dissociated and the double positive cells $\left[\right.$ calcein $^{+} \operatorname{DiIc}_{18}(3)^{+}$] were quantified by flow cytometry, using a FacsCalibur device (Becton-Dickinson, Mountain View, CA, USA). Doublepositive cells thus corresponded the functional calcein transfer from calcein ${ }^{+} \operatorname{DiIc}_{18}(3)^{-}$to calcein ${ }^{-} \operatorname{DiIc}_{18}(3)^{+}$ cells. At least $10^{4}$ cells were acquired in each experimental condition. In some experiments, TEC were also co-cultured with freshly isolated thymocytes. For this purpose, thymuses were obtained from BALC/c mice, maintained at the Oswaldo Cruz Foundation Animal Facilities (Rio de Janeiro, Brazil).

\section{RNA extraction and Northern Blotting}

Total RNA was extracted from the mouse TEC line, using TRIzol Reagent (Gibco/BRL, Grand Island, NY, USA). For northern blots, $10-20 \mu \mathrm{g}$ of total RNA was loaded in $1.2 \%$ agarose gel containing $0.12 \mathrm{mg} / \mathrm{L}$ ethidium bromide. Gels were blotted onto a nylon membrane and fixed by ultraviolet light. For detection of Cx43 mRNA, membranes were pre-hybridized for $1 \mathrm{hr}$ at $65^{\circ} \mathrm{C}$ in rapid hybridization buffer. Then the membrane was hybridized for $2 \mathrm{hrs}$ at $65^{\circ} \mathrm{C}$ with rapid hybridization buffer with a ${ }^{32} \mathrm{P}$-labeled cDNA probe for $\mathrm{Cx} 43$ or GAPDH. Membranes were washed once in $2 \times$ standard saline citrate buffer containing 0.1\% SDS at room temperature, then exposed to X-ray film.

\section{Statistics}

For statistical comparisons we applied the two- tail paired Student's $t$ test, implemented by the GraphPad Prism software. Differences with $\mathrm{p}<0.05$ were considered significant.

\section{Acknowledgements}

This study and authors was supported by grants from Conselho Nacional de Desenvolvimento Científico and Tecnológico (CNPq), Fundação de Amparo à Pesquisa do Estado do Rio de Janeiro (FAPERJ) and Fundação Oswaldo Cruz (Fiocruz)
}

\section{Author details \\ 'Laboratory of Cellular Communication, Oswaldo Cruz Institute, The Oswaldo Cruz Foundation, Rio de Janeiro, Brazil. 'Laboratory of Thymus Research, Oswaldo Cruz Institute, The Oswaldo Cruz Foundation, Rio de Janeiro, Brazil. ${ }^{3}$ Department of Pathology, Federal University of Rio de Janeiro State (UNIRIO), Rio de Janeiro, Brazil. ${ }^{4}$ Department of Clinical Analysis, Faculty of Pharmacy, Federal University of Juiz de Fora, Juiz de Fora, Brazil. ${ }^{5}$ Institute of Biophysics Carlos Chagas Filho, Federal University of Rio de Janeiro, Rio de Janeiro, Brazil. ${ }^{6}$ The Dominick P. Purpura Department of Neuroscience, Albert Einstein College of Medicine, New York, USA}

\section{Authors' contributions}

OKN - designed and performed flow cytometer and dye injection experiments, RNA extraction and Northern blotting experiments, analysed data and drafted the manuscript. PCF - designed and performed experiments. NMR - participated with expertise and participated in writing of the manuscript. AGB - participated with expertise, constructed the figures and participated in writing and review of the manuscript. JSPOL - designed and performed experiments. SNS - designed and performed experiments. ACCC - contributed reagents and expertise, DCS - participated in its design, participated in manuscript revision. WS - conceived of the study and contributed expertise. LAA - conceived of the study, analyzed data, and drafted the manuscript, and performed some dye injection experiments and Northern blotting experiments. All authors read and approved the final manuscript.

Received: 24 August 2009

Accepted: 15 January 2010 Published: 15 January 2010

\section{References}

1. Caveney S: The role of gap junctions in development. Annu Rev Physiol $1985,47: 319-335$.

2. Decrock E, Vinken M, De VE, Krysko DV, D'Herde K, Vanhaecke T, Vandenabeele $P$, Rogiers $V$, Leybaert L: Connexin-related signaling in cell death: to live or let die?. Cell Death Differ 2009, 16:524-536.

3. Hertzberg EL, Lawrence TS, Gilula NB: Gap junctional communication. Annu Rev Physiol 1981, 43:479-491.

4. Kardami E, Dang X, lacobas DA, Nickel BE, Jeyaraman M, Srisakuldee W, Makazan J, Tanguy S, Spray DC: The role of connexins in controlling cell growth and gene expression. Prog Biophys Mol Biol 2007, 94:245-264.

5. Loewenstein WR: Junctional intercellular communication: the cell-to-cell membrane channel. Physiol Rev 1981, 61:829-913.

6. Vinken M, Vanhaecke T, Papeleu P, Snykers S, Henkens T, Rogiers V: Connexins and their channels in cell growth and cell death. Cell Signal 2006, 18:592-600.

7. Vinken $M$, Vanhaecke $T$, Papeleu $P$, Snykers $S$, Henkens $T$, Rogiers V: Connexins and their channels in cell growth and cell death. Cell Signal 2006, 18:592-600.

8. Unger VM, Kumar NM, Gilula NB, Yeager M: Three-dimensional structure of a recombinant gap junction membrane channel. Science 1999, 283:1176-1180.

9. Perkins GA, Goodenough DA, Sosinsky GE: Formation of the gap junction intercellular channel requires a 30 degree rotation for interdigitating two apposing connexons. J Mol Biol 1998, 277:171-177.

10. Unwin PN, Zampighi G: Structure of the junction between communicating cells. Nature 1980, 283:545-549.

11. Shibata $Y$, Kumai M, Nishii K, Nakamura K: Diversity and molecular anatomy of gap junctions. Med Electron Microsc 2001, 34:153-159.

12. Sohl G, Willecke K: Gap junctions and the connexin protein family. Cardiovasc Res 2004, 62:228-232.

13. Yeager $M$, Nicholson BJ: Structure of gap junction intercellular channels. Curr Opin Struct Biol 1996, 6:183-192.

14. Bevans CG, Kordel M, Rhee SK, Harris AL: Isoform composition of connexin channels determines selectivity among second messengers and uncharged molecules. J Biol Chem 1998, 273:2808-2816.

15. Cole WC, Garfield RE: Evidence for physiological regulation of myometrial gap junction permeability. Am J Physiol 1986, 251:C411-C420.

16. Imanaga I: Cell-to-cell coupling studied by diffusional methods in myocardial cells. Experientia 1987, 43:1080-1083.

17. Saez JC, Connor JA, Spray DC, Bennett MV: Hepatocyte gap junctions are permeable to the second messenger, inositol 1,4,5-trisphosphate, and to calcium ions. Proc Natl Acad Sci USA 1989, 86:2708-2712.

18. Tsien RW, Weingart R: Inotropic effect of cyclic AMP in calf ventricular muscle studied by a cut end method. J Physiol 1976, 260:117-141.

19. Krysko DV, Leybaert L, Vandenabeele P, D'Herde K: Gap junctions and the propagation of cell survival and cell death signals. Apoptosis 2005, 10:459-469.

20. Sanderson MJ, Charles AC, Boitano S, Dirksen ER: Mechanisms and function of intercellular calcium signaling. Mol Cell Endocrinol 1994, 98:173-187.

21. Sheridan JD, Atkinson MM: Physiological roles of permeable junctions: some possibilities. Annu Rev Physiol 1985, 47:337-353.

22. Simon AM, Goodenough DA: Diverse functions of vertebrate gap junctions. Trends Cell Biol 1998, 8:477-483.

23. Alldredge B: Clinical connexions. J Clin Pathol 2008, 61:885-890

24. Cronier L, Crespin S, Strale PO, Defamie N, Mesnil M: Gap junctions and cancer: new functions for an old story. Antioxid Redox Signal 2009, 11:323-338.

25. Kelsell DP, Dunlop J, Hodgins MB: Human diseases: clues to cracking the connexin code?. Trends Cell Biol 2001, 11:2-6.

26. Laird DW: Connexin phosphorylation as a regulatory event linked to gap junction internalization and degradation. Biochim Biophys Acta 2005, 1711:172-182. 
27. Simon AM: Gap junctions: more roles and new structural data. Trends Cell Biol 1999, 9:169-170

28. White TW, Paul DL: Genetic diseases and gene knockouts reveal diverse connexin functions. Annu Rev Physiol 1999, 61:283-310

29. Spray DC, Scemes E: Effects of intracellular $\mathrm{pH}$ (and $\mathrm{Ca}^{2+}$ ) on gap junction channels. PH and Brain function New York, Wiley-Liss, IncKalai K, Ransom BR 1998, 477-489.

30. Spray DC, Bennett MV: Physiology and pharmacology of gap junctions. Annu Rev Physiol 1985, 47:281-303.

31. Lampe PD, Lau AF: Regulation of gap junctions by phosphorylation of connexins. Arch Biochem Biophys 2000, 384:205-215.

32. Branes MC, Contreras JE, Saez JC: Activation of human polymorphonuclear cells induces formation of functional gap junctions and expression of connexins. Med Sci Monit 2002, 8:BR313-BR323.

33. Eugenin EA, Eckardt D, Theis M, Willecke K, Bennett MV, Saez JC: Microglia at brain stab wounds express connexin 43 and in vitro form functional gap junctions after treatment with interferon-gamma and tumor necrosis factor-alpha. Proc Natl Acad Sci USA 2001, 98:4190-4195.

34. Eugenin EA, Branes MC, Berman JW, Saez JC: TNF-alpha plus IFN-gamma induce connexin43 expression and formation of gap junctions between human monocytes/macrophages that enhance physiological responses. J Immunol 2003, 170:1320-1328.

35. Inagaki-Ohara K, Sawaguchi A, Suganuma T, Matsuzaki G, Nawa Y: Intraepithelial lymphocytes express junctional molecules in murine small intestine. Biochem Biophys Res Commun 2005, 331:977-983.

36. Krenacs T, van DM, Lindhout E, Rosendaal M: Direct cell/cell communication in the lymphoid germinal center: connexin43 gap junctions functionally couple follicular dendritic cells to each other and to B lymphocytes. Eur J Immunol 1997, 27:1489-1497.

37. Matsue H, Yao J, Matsue K, Nagasaka A, Sugiyama H, Aoki R, Kitamura M, Shimada S: Gap junction-mediated intercellular communication between dendritic cells (DCs) is required for effective activation of DCs. J Immunol 2006, 176:181-190

38. Vliagoftis $\mathrm{H}$, Hutson AM, Mahmudi-Azer S, Kim H, Rumsaeng V, Oh CK Moqbel R, Metcalfe DD: Mast cells express connexins on their cytoplasmic membrane. J Allergy Clin Immunol 1999, 103:656-662.

39. Alves LA, Campos de Carvalho AC, Cirne Lima EO, Rocha e Souza CM, Dardenne M, Spray DC, Savino W: Functional gap junctions in thymic epithelial cells are formed by connexin 43. Eur J Immunol 1995, 25:431-437.

40. Ehmann UK, Calderwood SK, Stevenson MA: Gap-junctional communication between feeder cells and recipient normal epithelial cells correlates with growth stimulation. In Vitro Cell Dev Biol Anim 2001, 37:100-110.

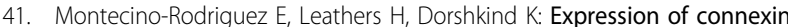
43 (Cx43) is critical for normal hematopoiesis. Blood 2000, 96:917-924.

42. Savino W, Dardenne M: Neuroendocrine control of thymus physiology. Endocr Rev 2000, 21:412-443.

43. Head GM, Mentlein R, Kranz A, Downing JE, Kendall MD: Modulation of dye-coupling and proliferation in cultured rat thymic epithelium by factors involved in thymulin secretion. J Anat 1997, 191(Pt 3):355-365.

44. Head GM, Mentlein R, von PB, Downing JE, Kendall MD: Neuropeptides exert direct effects on rat thymic epithelial cells in culture. Dev Immunol 1998, 6:95-104

45. Hanoune J, Defer N: Regulation and role of adenylyl cyclase isoforms. Annu Rev Pharmacol Toxicol 2001, 41:145-174.

46. Nishizuka Y: Intracellular signaling by hydrolysis of phospholipids and activation of protein kinase C. Science 1992, 258:607-614.

47. Francis SH, Corbin JD: Structure and function of cyclic nucleotidedependent protein kinases. Annu Rev Physiol 1994, 56:237-272.

48. Divecha N, Irvine RF: Phospholipid signaling. Cell 1995, 80:269-278.

49. Saez JC, Gregory WA, Watanabe T, Dermietzel R, Hertzberg EL, Reid L, Bennett MV, Spray DC: cAMP delays disappearance of gap junctions between pairs of rat hepatocytes in primary culture. Am J Physiol 1989, 257:C1-11.

50. Granot I, Dekel N: Phosphorylation and expression of connexin-43 ovarian gap junction protein are regulated by luteinizing hormone. J Bio Chem 1994, 269:30502-30509.

51. Darrow BJ, Fast VG, Kleber AG, Beyer EC, Saffitz JE: Functional and structural assessment of intercellular communication. Increased conduction velocity and enhanced connexin expression in dibutyryl cAMP-treated cultured cardiac myocytes. Circ Res 1996, 79:174-183.

52. Abudara V, Garces G, Saez JC: Cells of the carotid body express connexin43 which is up-regulated by cAMP. Brain Res 1999, 849:25-33.

53. Kojima A, Nakahama K, Ohno-Matsui K, Shimada N, Mori K, Iseki S, Sato T, Mochizuki M, Morita I: Connexin 43 contributes to differentiation of retinal pigment epithelial cells via cyclic AMP signaling. Biochem Biophys Res Commun 2008, 366:532-538.

54. Atkinson MM, Lampe PD, Lin HH, Kollander R, Li XR, Kiang DT: Cyclic AMP modifies the cellular distribution of connexin 43 and induces a persistent increase in the junctional permeability of mouse mammary tumor cells. J Cell Sci 1995, 108(Pt 9):3079-3090.

55. Burghardt RC, Barhoumi R, Sewall TC, Bowen JA: Cyclic AMP induces rapid increases in gap junction permeability and changes in the cellular distribution of connexin43. J Membr Biol 1995, 148:243-253.

56. Chanson M, Bruzzone R, Spray DC, Regazzi R, Meda P: Cell uncoupling and protein kinase $\mathrm{C}$ : correlation in a cell line but not in a differentiated tissue. Am J Physiol 1988, 255:C699-C704.

57. Romanello M, Moro L, Pirulli D, Crovella S, D'Andrea P: Effects of cAMP on intercellular coupling and osteoblast differentiation. Biochem Biophys Res Commun 2001, 282:1138-1144.

58. Lampe PD: Analyzing phorbol ester effects on gap junctional communication: a dramatic inhibition of assembly. J Cell Biol 1994, 127:1895-1905

59. Sirnes $\mathrm{S}$, Kjenseth $\mathrm{A}$, Leithe E, Rivedal E: Interplay between PKC and the MAP kinase pathway in Connexin43 phosphorylation and inhibition of gap junction intercellular communication. Biochem Biophys Res Commun 2009, 382:41-45

60. Sakai N, Blennerhassett MG, Garfield RE: Intracellular cyclic AMP concentration modulates gap junction permeability in parturient rat myometrium. Can J Physiol Pharmacol 1992, 70:358-364.

61. Fonseca PC, Nihei OK, Savino W, Spray DC, Alves LA: Flow cytometry analysis of gap junction-mediated cell-cell communication: advantages and pitfalls. Cytometry A 2006, 69:487-493.

62. Nihei OK, Campos de Carvalho AC, Spray DC, Savino W, Alves LA: A nove form of cellular communication among thymic epithelial cells: intercellular calcium wave propagation. Am J Physiol Cell Physiol 2003, 285:C1304-C1313.

63. Simonds WF: G protein regulation of adenylate cyclase. Trends Pharmacol Sci 1999, 20:66-73.

64. Bellinger DL, Lorton D, Horn L, Brouxhon S, Felten SY, Felten DL: Vasoactive intestinal polypeptide (VIP) innervation of rat spleen thymus, and lymph nodes. Peptides 1997, 18:1139-1149.

65. Reubi JC, Horisberger U, Kappeler A, Laissue JA: Localization of receptors for vasoactive intestinal peptide, somatostatin, and substance $P$ in distinct compartments of human lymphoid organs. Blood 1998, 92:191-197.

66. Apasov SG, Koshiba M, Chused TM, Sitkovsky MV: Effects of extracellular ATP and adenosine on different thymocyte subsets: possible role of ATP-gated channels and $\mathrm{G}$ protein-coupled purinergic receptor. $J$ Immunol 1997, 158:5095-5105.

67. Ralevic V, Burnstock G: Receptors for purines and pyrimidines. Pharmacol Rev 1998, 50:413-492

68. von PB, Kurz B, Mentlein R. Effect of transmitters and co-transmitters of the sympathetic nervous system on interleukin- 6 synthesis in thymic epithelial cells. Neuroimmunomodulation 1999, 6:45-50.

69. Pahujaa M, Anikin M, Goldberg GS: Phosphorylation of connexin43 induced by Src: regulation of gap junctional communication between transformed cells. Exp Cell Res 2007, 313:4083-4090.

70. Manley NR: Thymus organogenesis and molecular mechanisms of thymic epithelial cell differentiation. Semin Immunol 2000, 12:421-428.

71. Naquet $P$, Naspetti $M$, Boyd R: Development, organization and function of the thymic medulla in normal, immunodeficient or autoimmune mice. Semin Immunol 1999, 11:47-55.

72. Azarnia R, Dahl G, Loewenstein WR: Cell junction and cycle AMP: III. Promotion of junctional membrane permeability and junctional membrane particles in a junction-deficient cell type. J Membr Biol 1981, 63:133-146.

73. Traub O, Look J, Paul D, Willecke K: Cyclic adenosine monophosphate stimulates biosynthesis and phosphorylation of the $26 \mathrm{kDa}$ gap junction protein in cultured mouse hepatocytes. Eur J Cell Biol 1987, 43:48-54. 
74. Wang Y, Rose B: Clustering of Cx43 cell-to-cell channels into gap junction plaques: regulation by CAMP and microfilaments. J Cell Sci 1995, 108(Pt 11):3501-3508.

75. Burt JM, Spray DC: Inotropic agents modulate gap junctional conductance between cardiac myocytes. Am J Physiol 1988, 254 H1206-H1210.

76. Saez JC, Spray DC, Nairn AC, Hertzberg E, Greengard P, Bennett MV: cAMP increases junctional conductance and stimulates phosphorylation of the 27-kDa principal gap junction polypeptide. Proc Natl Acad Sci USA 1986, 83:2473-2477.

77. Van Rijen HV, van Veen TA, Hermans MM, Jongsma HJ: Human connexin40 gap junction channels are modulated by cAMP. Cardiovasc Res 2000, 45:941-951.

78. Marinissen MJ, Gutkind JS: G-protein-coupled receptors and signaling networks: emerging paradigms. Trends Pharmacol Sci 2001, 22:368-376.

79. Leposavic G, Pilipovic I, Radojevic K, Pesic V, Perisic M, Kosec D: Catecholamines as immunomodulators: a role for adrenoceptormediated mechanisms in fine tuning of T-cell development. Auton Neurosci 2008, 144:1-12.

80. Kurz B, Feindt J, von GB, Kranz A, Loppnow H, Mentlein R: Betaadrenoceptor-mediated effects in rat cultured thymic epithelial cells. $\mathrm{Br} J$ Pharmacol 1997, 120:1401-1408.

81. Tenbroek EM, Louis CF, Johnson R: The differential effects of 12-O tetradecanoylphorbol-13-acetate on the gap junctions and connexins of the developing mammalian lens. Dev Biol 1997, 191:88-102.

82. Cirne-Lima EO, van EW, Savino W: Cortical and medullary phenotypes within a mouse thymic epithelial cell line. In Vitro Cell Dev Biol Anim 1993, 29A:443-445

83. Dardenne M, Savino W, Gagnerault MC, Itoh T, Bach JF: Neuroendocrine control of thymic hormonal production. I. Prolactin stimulates in vivo and in vitro the production of thymulin by human and murine thymic epithelial cells. Endocrinology 1989, 125:3-12.

84. Itoh T, Doi H, Chin S, Nishimura T, Kasahara S: Establishment of mouse thymic nurse cell clones from a spontaneous BALB/c thymic tumor. Eur $J$ Immunol 1988, 18:821-824

85. Guyden JC, Pezzano M: Thymic nurse cells: a microenvironment for thymocyte development and selection. Int Rev Cytol 2003, 223:1-37.

86. Smaniotto S, de Mello-Coelho V, Villa-Verde DM, Pleau JM, Postel-Vinay MC, Dardenne M, Savino W: Growth hormone modulates thymocyte development in vivo through a combined action of laminin and CXC chemokine ligand 12. Endocrinology 2005, 146:3005-3017.

87. Kiang DT, Kollander R, Lin HH, LaVilla S, Atkinson MM: Measurement of gap junctional communication by fluorescence activated cell sorting. In Vitro Cell Dev Biol Anim 1994, 30A:796-802.

doi:10.1186/1471-2121-11-3

Cite this article as: Nihei et al:: Modulatory effects of CAMP and PKC activation on gap junctional intercellular communication among thymic epithelial cells. BMC Cell Biology 2010 11:3.

Publish with Biomed Central and every scientist can read your work free of charge

"BioMed Central will be the most significant development for disseminating the results of biomedical research in our lifetime. "

Sir Paul Nurse, Cancer Research UK

Your research papers will be:

- available free of charge to the entire biomedical community

- peer reviewed and published immediately upon acceptance

- cited in PubMed and archived on PubMed Central

- yours - you keep the copyright 